\title{
Using the Lower Limit of Normal Instead of the Conventional Cutoff Values to Define Predictors of Pulmonary Function Impairment in Subjects With Chronic Heart Failure
}

\author{
Armine G Minasian MD, Frank JJ van den Elshout MD PhD, PN Richard Dekhuijzen MD PhD, \\ Petra JE Vos MD PhD, Frank F Willems MD PhD, Paul JPC van den Bergh MD, and \\ Yvonne F Heijdra MD PhD
}

\begin{abstract}
BACKGROUND: Using the newer lower limit of normal criterion instead of the conventional cutoff values to define pulmonary function abnormalities may result in different predictors of pulmonary function impairment in patients with heart failure. Therefore, we assessed predictors of pulmonary function impairment in subjects with chronic heart failure according to the lower limit of normal in comparison with conventional cutoff values. METHODS: In this prospective cross-sectional study, 164 chronic heart failure subjects (age $68 \pm 10$ y, $78 \%$ men, $88 \%$ New York Heart Association class I-II) with left ventricular ejection fraction $<40 \%$ underwent pulmonary function tests. Predictors of pulmonary function impairment were assessed using the lower limit of normal and conventional cutoff values (ie, $80 \%$ predicted value and the fixed ratio of $\mathrm{FEV}_{\mathbf{1}} / \mathrm{FVC}<0.7$ ). RESULTS: The lower limit of normal criterion identified an extra independent predictor of diffusion impairment compared with the $80 \%$ predicted value; in addition to body mass index, pack-years, and alveolar volume, female sex also turned out to be an independent predictor. A smoking history of $\geq 10$ pack-years was a significant predictor of diffusion impairment and airway obstruction using the lower limit of normal criterion but not using the conventional cutoff values. However, lowering the cutoff points of conventional criteria to match the more stringent lower limit of normal and thus avoid overdiagnosis of diffusion impairment and airway obstruction in the elderly produced similar results as the lower limit of normal. CONCLUSIONS: The lower limit of normal identifies more predictors of diffusion impairment and airway obstruction compared with conventional cutoff values in subjects with chronic heart failure with left ventricular systolic dysfunction. However, lowering the conventional cutoff points yielded similar results as the lower limit of normal. (ClinicalTrials.gov registration NCT01429376.) Key words: Chronic heart failure, conventional cutoff values, lower limit of normal, predictors, pulmonary function impairment. [Respir Care 2016;61(2):173-183. @ 2016 Daedalus Enterprises]
\end{abstract}

\section{Introduction}

Isolated or combined pulmonary function abnormalities, such as restriction, diffusion impairment, and to a lesser

\footnotetext{
Drs Minasian, van den Elshout, and Vos are affiliated with the Department of Pulmonary Diseases, and Drs Willems and van den Bergh are affiliated with the Department of Cardiology, Rijnstate Hospital, Arnhem, The Netherlands. Drs Dekhuijzen and Heijdra are affiliated with the Department of Pulmonary Diseases, Radboud University Nijmegen Medical Centre, Nijmegen, The Netherlands.
}

This work was supported by an unrestricted grant from GlaxoSmithKline. The funding agency had no involvement in study design, data extent airway obstruction are common in patients with chronic heart failure ${ }^{1-7}$ and can contribute to the perception of dyspnea ${ }^{8}$ and exercise intolerance. ${ }^{8-12}$ Several factors have been implied to play a role in the etiology of pulmonary function impairment in patients with heart failure, including the effects of heart failure itself on pulmo-

\footnotetext{
collection, data analysis, interpretation of data, or writing of the report. The authors have disclosed no conflicts of interest.

Correspondence: Armine Minasian MD. Department of Pulmonary Diseases, Rijnstate Hospital, P.O. Box 9555, 6800 TA, Arnhem, The Netherlands. E-mail: aminasian@rijnstate.nl.
}

DOI: $10.4187 /$ respcare.04101 
nary function in addition to (previously undiagnosed) underlying pulmonary disease and confounding influences, such as smoking, coronary artery bypass grafting, and obesity. ${ }^{4-7,13}$ However, results are not consistent among the studies. For example, although smoking and a history of coronary artery bypass grafting were associated with more impaired pulmonary function in the study of Johnson et al, ${ }^{13}$ with also weak associations between left ventricular function and both lung volumes as well as diffusing capacity, none of the described pulmonary function abnormalities were found to be related to either smoking status, use of cardiac drugs, chest radiographic changes, hemodynamic findings, or clinical features, including the duration of heart failure in the study of Wright et al. ${ }^{14}$ Misdiagnosis of pulmonary function abnormalities may have interfered with the interpretation of prior research aiming to investigate the impact of heart failure and several clinical variables on pulmonary function in this group of patients. Traditionally, the $80 \%$ predicted value and the fixed ratio of $\mathrm{FEV}_{1} / \mathrm{FVC}<0.7$ have been used to define pulmonary function abnormalities. However, these conventional cutoff values have neither statistical nor physiological validity ${ }^{15-17}$ and may misclassify $>20 \%$ of patients, leading to false-positive diagnosis in the elderly and underdiagnosis in younger patients. ${ }^{18}$ To avoid misclassification, recent American Thoracic Society/European Respiratory Society guidelines ${ }^{16}$ recommend the use of statistically derived lower limit of normal values that are based on the normal distribution and that classify the bottom $5 \%$ of the healthy population as abnormal. However, studies using the lower limit of normal to assess predictors of pulmonary function impairment in patients with chronic heart failure are lacking. Therefore, the purpose of this study was to assess predictors of pulmonary function impairment in subjects with chronic heart failure according to the lower limit of normal in comparison with conventional cutoff values (percent of predicted and the fixed ratio of $\mathrm{FEV}_{1} / \mathrm{FVC}$ ).

\section{Methods}

\section{Study Design and Participants}

This study was part of a larger prospective cross-sectional study evaluating the prevalence of COPD in subjects with chronic heart failure. All patients visiting 2 outpatient cardiology departments of a large hospital in The Netherlands were screened for inclusion between October 2009 and December 2010. Inclusion criteria were chronic heart failure ${ }^{19}$ with left ventricular systolic dysfunction (ie, left ventricular ejection fraction $<40 \%$ ) and New York Heart Association (NYHA) class I-IV. Chronic heart failure was defined according to the European Society of Cardiology guidelines. ${ }^{19}$ Echocardiography was performed

\section{QUICK LOOK}

\section{Current knowledge}

Isolated or combined pulmonary function abnormalities are common in patients with chronic heart failure. Traditionally, the $80 \%$ predicted value and a fixed ratio of $\mathrm{FEV}_{1} / \mathrm{FVC}<0.7$ have been used to define pulmonary function abnormalities. However, compared with the newer lower limit of normal criterion, these conventional cutoff values may misclassify $>20 \%$ of patients, leading to false-positive diagnosis in the elderly and underdiagnosis in younger patients. Misdiagnosis of pulmonary function abnormalities may have interfered with the search for predictors of pulmonary function impairment in patients with chronic heart failure.

\section{What this paper contributes to our knowledge}

The lower limit of normal identified more predictors of diffusion impairment and airway obstruction compared with conventional cutoff values in subjects with chronic heart failure with left ventricular systolic dysfunction. The lower limit of normal identified sex as an extra predictor of diffusion impairment and a smoking history of $\geq 10$ pack-years as an additional predictor of both diffusion impairment and airway obstruction. Lowering the conventional cutoff points yielded similar results as the lower limit of normal.

in subjects without a recent ( $\leq 6$ months) test to confirm persisting left ventricular systolic dysfunction. Subjects who were not able to cooperate or undergo spirometry or who had a history of asthma were excluded. Other exclusion criteria were malignancy with a poor prognosis (survival $<6$ months) and participation in another study. For the current study, we also excluded subjects with known pulmonary (including COPD), pleural (with the exception of pleural effusion due to heart failure), neuromuscular, collagen vascular, or other diseases that could affect pulmonary function. Subjects with a body mass index (BMI) $>35$ were excluded from the restriction prevalence analysis. The study was approved by the regional Research Ethics Committee Arnhem-Nijmegen in The Netherlands (2009/101, NL27798.091.09) and complied with the Declaration of Helsinki. All subjects gave written informed consent.

Subjects were classified as having stable heart failure in the absence of hospitalization due to progression of heart failure within 3 months, change in diuretics within 1 month, $3 \%$ or more weight gain within $3 \mathrm{~d}$, and $>50 \%$ increase of $\mathrm{N}$-terminal pro-B natriuretic peptide (NT-proBNP) within 1 month when the baseline NT-proBNP was $100 \mathrm{pmol} / \mathrm{L}$ or higher or $>100 \mathrm{pmol} / \mathrm{L}$ increase of NT-proBNP within 1 month when baseline NT-proBNP was below $100 \mathrm{pmol} / \mathrm{L} .{ }^{20}$ 


\section{Measurements and Data Collection}

At baseline, a first blood sample was taken for the measurement of NT-proBNP. One month later, the participants visited the hospital for an interview with the investigator and several examinations, including height and weight measurement, pulmonary function tests, a chest radiograph, and a second blood sample (hemoglobin, NT-proBNP). Additional data were collected from medical records and personal interviews. Smoking status was defined as never ( $<100$ cigarettes in a lifetime), former ( $\geq 3$ months ago), or current smoker $(<3$ months ago). Smoking pack-years were based only on the tobacco cigarette history, and 1 pack-year was defined as smoking 20 cigarettes/d for $1 \mathrm{y}$. Dyspnea was defined as resting dyspnea or dyspnea at any level of exertion.

\section{Pulmonary Function Tests}

All participants underwent pre-bronchodilator spirometry (MasterLab Pro, Jaeger, Würzburg, Germany) and measurement of diffusing capacity of the lungs for carbon monoxide $\left(\mathrm{D}_{\mathrm{LCO}} \mathrm{c}\right)$. $\mathrm{D}_{\mathrm{LCO}}$ was measured with the standard single-breath technique and was corrected for the subject's hemoglobin concentration $\left(\mathrm{D}_{\mathrm{LCO}} \mathrm{c}\right)$. During the measurement of $\mathrm{D}_{\mathrm{LCO}}$, the alveolar volume $\left(\mathrm{V}_{\mathrm{A}}\right)$ was also obtained, and the $\mathrm{D}_{\mathrm{LCO}} \mathrm{c}$ was corrected for the $\mathrm{V}_{\mathrm{A}}\left(\mathrm{D}_{\mathrm{LCO}} \mathrm{c} / \mathrm{V}_{\mathrm{A}}\right)$ (ie, transfer coefficient for carbon monoxide). Body plethysmography was performed in subjects with airway obstruction according to either definition to assess the presence of hyperinflation. In addition, it was performed in subjects with signs of restriction on spirometry (ie, [F]VC $<$ lower limit of normal and/or $<80 \%$ predicted with normal $\mathrm{FEV}_{1} /[\mathrm{F}] \mathrm{VC}$ ratio) to confirm suspected restriction by measuring the total lung capacity (TLC). In other cases, body plethysmography was omitted, since abnormal findings of body plethysmography were not expected with normal spirometry results. Pulmonary function tests were performed by trained and certified operators using standard techniques and according to the European Respiratory Society standards for acceptability and reproducibility. ${ }^{21}$ The European Community for Coal and Steel reference equations were used to calculate predicted values. ${ }^{21}$

Diffusion impairment was defined as $\mathrm{D}_{\mathrm{LCO}} \mathrm{c}<$ lower limit of normal (American Thoracic Society/European Respiratory Society) ${ }^{16}$ and $<80 \%$ predicted (conventional cutoff value). Restriction was defined as TLC $<$ lower limit of normal (American Thoracic Society/European Respiratory Society) ${ }^{16}$ and $<80 \%$ predicted (conventional cutoff value). Airway obstruction was defined as $\mathrm{FEV}_{1} / \mathrm{VC}<$ lower limit of normal (American Thoracic Society/European Respiratory Society) ${ }^{16}$ and $\mathrm{FEV}_{1} / \mathrm{FVC}<0.7$ (conventional cutoff value). ${ }^{22} \mathrm{VC}$ was regarded as the largest vital capacity (either slow, forced, inspiratory, or expiratory). The lower
Table 1. Regression Equations for Calculation of Predicted Values and Lower Limit of Normal for Adult Men and Women

\begin{tabular}{|c|c|c|}
\hline Variable & Regression Equation & $\begin{array}{c}1.64 \times \\
\text { Residual SD }\end{array}$ \\
\hline \multicolumn{3}{|l|}{$\mathrm{FEV}_{1} / \mathrm{FVC}, \%$} \\
\hline Men & $-0.18 \mathrm{~A}+87.21$ & 11.8 \\
\hline Women & $-0.19 A+89.10$ & 10.7 \\
\hline \multicolumn{3}{|l|}{ TLC, L } \\
\hline Men & $7.99 \mathrm{H}-7.08$ & 1.15 \\
\hline Women & $6.60 \mathrm{H}-5.79$ & 0.99 \\
\hline \multicolumn{3}{|c|}{$\mathrm{D}_{\mathrm{LCO}}, \mathrm{mL} / \mathrm{min} / \mathrm{mmHg}$} \\
\hline Men & $33.19 \mathrm{H}-0.197 \mathrm{~A}-18.01$ & 6.93 \\
\hline Women & $24.43 \mathrm{H}-0.146 \mathrm{~A}-8.18$ & 5.74 \\
\hline $\begin{array}{l}\text { The lower limit of no } \\
\text { the predicted value. } \\
A=\text { age } \\
\mathrm{H}=\text { height } \\
\mathrm{TLC}=\text { total lung cap } \\
\mathrm{D}_{\mathrm{LCO}} \mathrm{C}=\text { diffusing ca }\end{array}$ & ulated by subtracting $1.64 \times$ residual $s$ & ast column) from \\
\hline
\end{tabular}

limit of normal was regarded as the lower 5th percentile of the frequency distribution of a healthy reference population, and it was calculated by subtracting 1.64 times the residual SD from the predicted value (Table 1). Hyperinflation was defined as the absolute ratio of residual volume to TLC $>40 \% .^{23}$

\section{Chest Radiographs}

Standard posterior-anterior and lateral chest radiographs were performed and evaluated for the presence or absence of cardiomegaly (cardiothoracic ratio $>0.5$ ), congestion (alveolar edema, pleural effusion, Kerley-B lines, and/or redistribution of pulmonary blood flow), and conditions that belonged to the exclusion criteria. Independent radiologists qualitatively assessed the chest radiographs with an overall clinical impression.

\section{Statistical Analysis}

Descriptive data are presented as the mean \pm SD or as $n(\%)$. Differences in the prevalence of pulmonary function abnormalities according to different definitions were analyzed with the McNemar test, which compares paired proportions. Differences between groups were analyzed using an independent $t$ test for continuous variables and a chi-square or Fisher exact test for categorical variables, as appropriate. Differences in pulmonary function between groups of subjects according to NYHA class were analyzed with an independent analysis of variance. Post hoc analyses were performed using the Fisher least-significant difference test when the assumption of homogeneity of variance was met. The least-significant difference pairwise 
Table 2. Subjects' Characteristics

\begin{tabular}{|c|c|}
\hline Characteristics & Values \\
\hline Age, y & $68 \pm 10$ \\
\hline Male sex, $n(\%)$ & $128(78)$ \\
\hline BMI, $\mathrm{kg} / \mathrm{m}^{2}$ & $28 \pm 5$ \\
\hline LVEF, \% & $28 \pm 7$ \\
\hline \multicolumn{2}{|l|}{ NYHA class, $n(\%)$} \\
\hline NYHA I & $28(17)$ \\
\hline NYHA II & $117(71)$ \\
\hline NYHA III & $19(12)$ \\
\hline Stable heart failure, $n(\%)$ & $141(86)$ \\
\hline Congestion, $n(\%)$ & $18(11)$ \\
\hline Pleural effusion, $n(\%)$ & $12(7)$ \\
\hline Cardiomegaly, $n(\%)$ & $97(59)$ \\
\hline Ischemic etiology, $n(\%)$ & $98(60)$ \\
\hline \multicolumn{2}{|l|}{ Smoking history } \\
\hline Non-smoker, $n(\%)$ & $35(21)$ \\
\hline Current smoker, $n(\%)$ & $23(14)$ \\
\hline Former smoker, $n(\%)$ & $106(65)$ \\
\hline Pack-years, y & $19 \pm 20$ \\
\hline Dyspnea, $n(\%)$ & $132(80)$ \\
\hline \multicolumn{2}{|l|}{ Co-morbidity, $n(\%)$} \\
\hline Myocardial infarction & $99(60)$ \\
\hline Atrial fibrillation & $57(35)$ \\
\hline Hypertension & $66(40)$ \\
\hline Diabetes mellitus & $40(24)$ \\
\hline $\mathrm{PCI} /$ coronary artery bypass grafting & $67(41)$ \\
\hline CRT/ICD & $52(32)$ \\
\hline \multicolumn{2}{|l|}{ Medication, $n(\%)$} \\
\hline ACE-I/ARB & $153(93)$ \\
\hline$\beta$-Blockers & $149(91)$ \\
\hline Diuretics & $135(82)$ \\
\hline Aldosterone antagonists & $63(38)$ \\
\hline Digoxin & $20(12)$ \\
\hline \multicolumn{2}{|l|}{ Laboratory data } \\
\hline NT-proBNP 1, pmol/L & $236 \pm 316$ \\
\hline NT-proBNP 2, pmol/L & $250 \pm 375$ \\
\hline Hemoglobin, mmol/L & $8.6 \pm 1.0$ \\
\hline $\begin{array}{l}N=164 \text {. Data are presented as the mean } \pm \text { SD } \\
\text { BMI = body mass index } \\
\text { LVEF = left ventricular ejection fraction } \\
\text { NYHA = New York Heart Association } \\
\text { PCI = percutaneous coronary intervention } \\
\text { CRT/ICD }=\text { cardiac resynchronization therapy/ir } \\
\text { ACE-I/ARB = angiotensin-converting enzyme in } \\
\text { NT-proBNP = N-terminal pro-B natriuretic pept }\end{array}$ & $\begin{array}{l}\text { lator } \\
\text { ocker }\end{array}$ \\
\hline
\end{tabular}

comparison is equivalent to performing multiple $t$ tests on the data. However, it requires the overall analysis of variance to be significant, and therefore the type- 1 error is limited to a maximum of $5 \%$. The Games-Howell test was used when the assumption of homogeneity of variance was not met, and it was chosen because of unequal sample sizes. Univariate and multivariate logistic regression analysis was performed to identify independent predictors of diffusion impairment according to different definitions.
Table 3. Pulmonary Function Test Results

\begin{tabular}{|c|c|}
\hline Pulmonary Function Tests & Results \\
\hline \multicolumn{2}{|l|}{ Spirometry $(n=164)$} \\
\hline $\mathrm{FEV}_{1}, \mathrm{~L}$ & $2.7 \pm 0.8(93 \pm 18)$ \\
\hline $\mathrm{VC}, \mathrm{L}$ & $4.0 \pm 1.0(104 \pm 17)$ \\
\hline $\mathrm{FEV}_{1} / \mathrm{VC}, \%$ & $68 \pm 8.0$ \\
\hline \multicolumn{2}{|l|}{ Diffusing capacity $(n=153)$} \\
\hline $\mathrm{D}_{\mathrm{LCO}} \mathrm{c}, \mathrm{mL} / \mathrm{min} / \mathrm{mmHg}$ & $20.01 \pm 5.68(76 \pm 16)$ \\
\hline $\mathrm{D}_{\mathrm{LCO}} \mathrm{c} / \mathrm{V}_{\mathrm{A}}, \mathrm{mL} / \mathrm{min} / \mathrm{mmHg} / \mathrm{L}$ & $3.58 \pm 0.90(90 \pm 20)$ \\
\hline $\mathrm{V}_{\mathrm{A}}, \mathrm{L}$ & $5.7 \pm 1.3(88 \pm 13)$ \\
\hline \multicolumn{2}{|l|}{ Body plethysmography $(n=70)^{*}$} \\
\hline TLC, L & $6.7 \pm 1.3(100 \pm 16)$ \\
\hline $\mathrm{RV}, \mathrm{L}$ & $2.7 \pm 0.6(107 \pm 24)$ \\
\hline RV/TLC, \% & $40 \pm 7(99 \pm 18)$ \\
\hline ITGV, L & $4.0 \pm 0.9(112 \pm 21)$ \\
\hline $\mathrm{R}_{\mathrm{aw}}, \mathrm{kPa} \mathrm{L} \mathrm{L}^{-1} \mathrm{~s}$ & $0.4 \pm 0.2(121 \pm 60)$ \\
\hline $\mathrm{sG}_{\mathrm{aw}}, \mathrm{kPa}^{-1} \mathrm{~s}^{-1}$ & $0.9 \pm 0.4(98 \pm 45)$ \\
\hline \multicolumn{2}{|c|}{$\begin{array}{l}\text { Data are presented as the mean } \pm \mathrm{SD} \text { (percent predicted } \pm \mathrm{SD} \text { ). Pulmonary function data, } \\
\text { with the exception of } \mathrm{FEV}_{1} / \mathrm{VC} \text {, are expressed as absolute values and percent predicted based } \\
\text { on age, height, and sex. }\end{array}$} \\
\hline \multicolumn{2}{|c|}{$\begin{array}{l}\text { * Reasons for performing body plethysmography: airway obstruction }(n=58) \text {, signs of } \\
\text { restriction }(n=5) \text {, signs of mixed pulmonary dysfunction }(n=7) \text {. } \\
\text { VC = largest vital capacity }\end{array}$} \\
\hline \multirow{2}{*}{\multicolumn{2}{|c|}{$\mathrm{D}_{\mathrm{LCO}} \mathrm{C}=$ diffusing capacity for carbon monoxide }} \\
\hline \multirow{2}{*}{$\begin{array}{l}\mathrm{V}_{\mathrm{A}}=\text { alveolar volume } \\
\mathrm{TLC}=\text { total lung capacity }\end{array}$} & \\
\hline & \\
\hline \multicolumn{2}{|l|}{$\mathrm{RV}=$ residual volume } \\
\hline \multicolumn{2}{|l|}{$\mathrm{ITGV}=$ intrathoracic gas volume } \\
\hline \multicolumn{2}{|l|}{$\begin{array}{l}\mathrm{R}_{\mathrm{aw}}=\text { airway resistance } \\
\mathrm{sG}_{\mathrm{aw}}=\text { specific airway conductance }\end{array}$} \\
\hline
\end{tabular}

All variables of interest with a univariate $P<.05$ were included in the multivariate analysis. Statistical analyses were performed using SPSS 21.0 (SPSS, Chicago, Illinois). All statistical tests were 2-sided, and $P<.05$ was considered significant.

\section{Results}

\section{Subject Characteristics}

After screening of the entire heart failure population, a cohort of 164 chronic heart failure subjects was selected for the current study, of whom $78 \%$ were men (Table 2). The mean age was $68 \pm 10 \mathrm{y}$, and the mean left ventricular ejection fraction was $28 \pm 7 \%$. Seventeen percent were in NYHA class I, $71 \%$ in NYHA class II, and $12 \%$ in NYHA class III. The majority had stable chronic heart failure (86\%) without signs of congestion on chest radiograph $(89 \%)$. Other subject characteristics and results of pulmonary function tests are presented in Tables 2 and 3, respectively.

Reliable diffusion measurement could not be obtained in 11 subjects. These subjects were included only in the airway obstruction and restriction prevalence analysis. Similarly, reliable body plethysmography results could 
Table 4. Prevalence of Pulmonary Function Impairment According to Smoking Status and Sex Using the Lower Limit of Normal Versus (Adjusted) Conventional Cutoff Values

\begin{tabular}{|c|c|c|c|c|c|c|c|c|c|c|}
\hline & $\begin{array}{c}\text { All } \\
(N=164)\end{array}$ & $\begin{array}{c}\text { NS } \\
(n=35)\end{array}$ & $\begin{array}{c}\text { FS/CS } \\
(n=129)\end{array}$ & $P$ & $\begin{array}{c}\mathrm{PY}<10 \\
(n=64)\end{array}$ & $\begin{array}{l}P Y \geq 10 \\
(n=100)\end{array}$ & $P$ & $\begin{array}{c}\text { Men } \\
(n=128) \\
\end{array}$ & $\begin{array}{c}\text { Women } \\
(n=36)\end{array}$ & $P$ \\
\hline \multicolumn{11}{|l|}{ Diffusion impairment* } \\
\hline Lower limit of normal & 44 & 41 & 46 & .63 & 35 & 51 & .05 & 40 & 61 & .04 \\
\hline Conventional cutoff values & 58 & 53 & 59 & .57 & 50 & 62 & .14 & 54 & 70 & .11 \\
\hline Adjusted conventional cutoff values $\dagger$ & NA & NA & NA & NA & 33 & 51 & .03 & 33 & 58 & .01 \\
\hline \multicolumn{11}{|l|}{ Airway obstruction } \\
\hline Lower limit of normal & 26 & 14 & 29 & .08 & 17 & 31 & .05 & 27 & 19 & .34 \\
\hline Conventional cutoff values & 37 & 26 & 40 & .11 & 33 & 40 & .35 & 41 & 25 & .09 \\
\hline Adjusted conventional cutoff values $\dagger$ & NA & NA & NA & NA & 9 & 27 & .01 & NA & NA & NA \\
\hline \multicolumn{11}{|l|}{ Restriction* } \\
\hline Lower limit of normal & 7 & 7 & 7 & $>.99$ & 7 & 7 & $>.99$ & 9 & 0 & .12 \\
\hline Conventional cutoff values & 5 & 3 & 6 & .70 & 3 & 6 & .49 & 7 & 0 & .21 \\
\hline $\begin{array}{l}\text { Data are presented as percentages. } \\
* \text { Analysis was performed in a total of } 153 \text { subjects. } \\
\dagger D_{\text {LCOC }}<75 \% \text { for PY and }<70 \% \text { for gender differ } \\
\text { NS }=\text { non-smokers } \\
\text { FS }=\text { former smokers } \\
\text { CS }=\text { current smokers } \\
\text { PY = pack-years } \\
\text { NA }=\text { not applicable }\end{array}$ & nces. $\mathrm{FEV}_{1} / \mathrm{FVC}$ & atio $<0.65$. & & & & & & & & \\
\hline
\end{tabular}

not be obtained in 3 subjects. Two of these subjects were consequently excluded from the restriction prevalence analysis, because suspected restriction on spirometry could not be confirmed by reliable body plethysmography results. Nine subjects had a BMI of $>35$ and were subsequently excluded from the restriction prevalence analysis.

\section{Pulmonary Function Impairment}

Prevalence rates of pulmonary function impairment are shown in Table 4. The most noted pulmonary function abnormality was diffusion impairment, which was more prevalent using the conventional cutoff value of $80 \%$ predicted instead of the lower limit of normal (58\% vs $44 \%$, respectively; $P<.001$ ). The second most prevalent abnormality was airway obstruction, which was more frequent using the fixed ratio of 0.7 instead of the lower limit of normal (37\% vs $26 \%$, respectively; $P=.002$ ). In contrast to the high occurrence of diffusion impairment and airway obstruction, restriction was infrequent, irrespective of the definition used (5\% vs 7\%, respectively; $P=.25$ ). This was also true when the 2 subjects with suspected restriction on spirometry but without a reliable body plethysmography result to confirm this were regarded as having restriction (7\% vs $8 \%$, respectively; $P=.25$ ). Hyperinflation was present in $46 \%$ of 65 subjects with airway obstruction or signs of mixed pulmonary dysfunction on spirometry who performed body plethysmography. The definition used for airway obstruction did not impact the occurrence of hyperinflation.
The frequency of pulmonary function abnormalities according to either definition was not significantly different between current/former smokers and non-smokers. However, subjects who had smoked $\geq 10$ pack-years had diffusion impairment and airway obstruction more often compared with those with $<10$ pack-years using the lower limit of normal (51\% vs $35 \%$ and $31 \%$ vs $17 \%$, respectively; $P=.05)$. The significance of this relationship was lost when using conventional cutoff values (62\% vs $50 \%$ $[P=.14]$ and $40 \%$ vs $33 \%[P=.35]$, respectively). On the other hand, lowering the conventional cutoff value to $75 \%$ for diffusion impairment $\left(\mathrm{D}_{\mathrm{LCO}} \mathrm{c}<75 \%\right.$ predicted $)$ and 0.65 for airway obstruction $\left(\mathrm{FEV}_{1} / \mathrm{FVC}\right.$ ratio $\left.<0.65\right)$ yielded significant differences in the occurrence of diffusion impairment and airway obstruction when comparing groups of subjects who had smoked $\geq 10$ pack-years versus $<10$ pack-years $(51 \%$ vs $33 \%[P=.03]$ and $27 \%$ vs $9 \%[P=.01]$, respectively). The frequency of airway obstruction according to either definition was not significantly different between men and women (lower limit of normal: $27 \%$ vs $19 \%$, respectively, $P=.34$; fixed ratio of 0.7: $41 \%$ vs $25 \%$, respectively, $P=.09$ ). However, although the frequency of diffusion impairment according to the $80 \%$ predicted value was not significantly different between men and women (54\% vs $70 \%$, respectively; $P=.11$ ), women had diffusion impairment significantly more often than men using the lower limit of normal $(61 \%$ vs $40 \%$, respectively; $P=.04$ ). Lowering the conventional cutoff value to $70 \%\left(\mathrm{D}_{\mathrm{LCO}} \mathrm{c}<70 \%\right.$ predicted) yielded significant differences between women and men in the oc- 
Table 5. Pulmonary Function Test Results According to New York Heart Association Class

\begin{tabular}{|c|c|c|c|c|c|}
\hline & $\begin{array}{l}\text { Total group } \\
(N=164)\end{array}$ & $\begin{array}{l}\text { NYHA I } \\
(n=28)\end{array}$ & $\begin{array}{l}\text { NYHA II } \\
(n=117)\end{array}$ & $\begin{array}{l}\text { NYHA III } \\
(n=19)\end{array}$ & $P$ \\
\hline $\mathrm{FEV}_{1}, \%$ predicted & $93 \pm 18$ & $98 \pm 18^{\dagger}$ & $94 \pm 17$ & $84 \pm 19$ & .03 \\
\hline $\mathrm{VC}, \%$ predicted & $104 \pm 17$ & $107 \pm 16$ & $104 \pm 16$ & $97 \pm 21$ & .12 \\
\hline $\mathrm{FEV}_{1} / \mathrm{VC}, \%$ & $68 \pm 8.0$ & $68 \pm 8$ & $68 \pm 8$ & $68 \pm 9$ & .91 \\
\hline $\mathrm{D}_{\mathrm{LCO}} \mathrm{c}, \%$ predicted ${ }^{\ddagger}$ & $76 \pm 16$ & $85 \pm 10^{* \dagger}$ & $74 \pm 16$ & $73 \pm 15$ & $<.001$ \\
\hline $\mathrm{D}_{\mathrm{LCO}} \mathrm{c} / \mathrm{V}_{\mathrm{A}}, \%$ predicted $^{\neq}$ & $90 \pm 20$ & $94 \pm 15$ & $88 \pm 20$ & $92 \pm 23$ & .33 \\
\hline $\mathrm{V}_{\mathrm{A}}, \%$ predicted $^{\ddagger}$ & $88 \pm 13$ & $94 \pm 10^{*}$ & $88 \pm 13$ & $83 \pm 15$ & .03 \\
\hline
\end{tabular}

Data are presented as mean \pm SD. $P$ values refer to differences in pulmonary function between groups of subjects according to New York Heart Association class (independent analysis of variance)

$* P<.05$, NYHA class I versus NYHA class II.

$\dagger P<.05$, NYHA class I versus NYHA class III. No significant differences in pulmonary function were found between NYHA classes II and III.

\# Analysis was performed in a total of 153 subjects.

NYHA $=$ New York Heart Association

$\mathrm{VC}=$ largest vital capacity

$\mathrm{D}_{\mathrm{LCO}} \mathrm{c}=$ diffusing capacity for carbon monoxide corrected for hemoglobin concentration

$\mathrm{V}_{\mathrm{A}}=$ alveolar volume

Table 6. Pulmonary Function Test Results According to Smoking Status

\begin{tabular}{lcccc}
\hline \hline & $\begin{array}{c}\text { Total Group } \\
(N=164)\end{array}$ & $\begin{array}{c}\mathrm{PY}<10 \\
(n=64)\end{array}$ & $\begin{array}{c}\mathrm{PY} \geq 10 \\
(n=100)\end{array}$ & $P$ \\
\hline $\mathrm{FEV}_{1}, \%$ predicted & $93 \pm 18$ & $97 \pm 19$ & $91 \pm 17$ & .05 \\
$\mathrm{VC} \%$ predicted & $104 \pm 17$ & $105 \pm 19$ & $103 \pm 15$ & .39 \\
$\mathrm{FEV}_{1} / \mathrm{VC}, \%$ & $68 \pm 8.0$ & $69 \pm 7$ & $67 \pm 9$ & .04 \\
$\mathrm{D}_{\mathrm{LCO}} \mathrm{c}, \%$ predicted* & $76 \pm 16$ & $80 \pm 13$ & $74 \pm 17$ & .02 \\
$\mathrm{D}_{\mathrm{LCO}} / \mathrm{V}_{\mathrm{A}}, \%$ predicted* & $90 \pm 20$ & $93 \pm 17$ & $88 \pm 21$ & .10 \\
$\mathrm{~V}_{\mathrm{A}}, \%$ predicted* & $88 \pm 13$ & $89 \pm 13$ & $88 \pm 13$ & .49
\end{tabular}

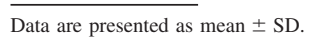

* Analysis was performed in a total of 153 subjects.

$\mathrm{PY}=$ pack-years

$\mathrm{VC}=$ largest vital capacity

$\mathrm{D}_{\mathrm{LCO}} \mathrm{c}=$ diffusing capacity for carbon monoxide corrected for hemoglobin concentration

$\mathrm{V}_{\mathrm{A}}=$ alveolar volume

currence of diffusion impairment (58\% vs 33\%, respectively; $P=.01$ ).

Subjects with a higher NYHA class had lower $\mathrm{FEV}_{1}$, $\mathrm{D}_{\text {LCO }} \mathrm{c}$, and $\mathrm{V}_{\mathrm{A}}$ (Table 5). Subjects who had smoked $\geq 10$ pack-years had lower $\mathrm{FEV}_{1}, \mathrm{FEV}_{1} / \mathrm{VC}$ ratio, and $\mathrm{D}_{\mathrm{LCO}} \mathrm{c}$ than those with $<10$ pack-years (Table 6). Subjects with pulmonary congestion, pleural effusion, or cardiomegaly on chest radiograph had lower lung volumes and diffusing capacity than those without pulmonary congestion, pleural effusion, or cardiomegaly (Table 7 ). $\mathrm{D}_{\mathrm{LCO}} \mathrm{c}$ corrected for $\mathrm{V}_{\mathrm{A}}$, however, was comparable between the groups. A history of coronary artery bypass grafting was associated with lower lung volumes.

\section{Univariate and Multivariate Logistic Regression Analysis}

Since the most frequently observed abnormality in pulmonary function was diffusion impairment, we performed a univariate and multivariate logistic regression analysis to identify independent predictors of diffusion impairment according to different definitions (Table 8). All variables of interest with a univariate $P<.05$ were included in the multivariate analysis. These included female sex, BMI, pack-years, NT-proBNP, and $\mathrm{V}_{\mathrm{A}}$ to identify independent predictors of diffusion impairment according to the lower limit of normal. In addition, BMI, cardiomegaly, packyears, NT-proBNP, and $\mathrm{V}_{\mathrm{A}}$ were included to identify independent predictors of diffusion impairment according to the $80 \%$ predicted value. Multivariate analysis showed female sex, BMI, pack-years (continuous variable), and $\mathrm{V}_{\mathrm{A}}$ to be independent predictors of diffusion impairment according to the lower limit of normal. Similar variables were found to be associated with diffusion impairment according to the $80 \%$ predicted value, except for female sex. However, female sex became an independent predictor of diffusion impairment after lowering the conventional cutoff value to $70 \%\left(\mathrm{D}_{\mathrm{LCO}} \mathrm{c}<70 \%\right.$ predicted, odds ratio [CI] of 3.68 [1.55-8.72], $P<.001)$. Pack-years as a dichotomous variable $(<10$ or $\geq 10)$ was an independent predictor of diffusion impairment according to the lower limit of normal (multivariate odds ratio [CI] of 2.32 [1.114.87], $P=.03$ ) but not according to the $80 \%$ predicted value (univariate odds ratio [CI] of 1.64 [0.85-3.17], $P=.14$ ). However, smoking $\geq 10$ pack-years became an independent predictor of diffusion impairment after lowering the conventional cutoff value to $75 \%\left(\mathrm{D}_{\mathrm{LCO}} \mathrm{c}<75 \%\right.$ predicted, multivariate odds ratio $[\mathrm{CI}]$ of 2.72 [1.27-5.85], $P=.01)$.

A smoking history of $\geq 10$ pack-years was a significant predictor of airway obstruction (univariate logistic analysis) using the lower limit of normal criterion (odds ratio [CI] of 2.17 [1.00-4.70], $P=.05)$ but not using the fixed ratio of 0.7 (odds ratio [CI] of 1.37 [0.71-2.64], $P=.35$ ). However, smoking $\geq 10$ pack-years became a significant predictor of airway obstruction after lowering the fixed 


\section{Predictors of Pulmonary Function Impairment in Chronic Heart Failure}

Table 7. Pulmonary Function Test Results According to the Presence or Absence of Pulmonary Congestion, Pleural Effusion, Cardiomegaly, and a History of Coronary Artery Bypass Grafting

\begin{tabular}{|c|c|c|c|c|c|c|c|c|c|}
\hline & $\begin{array}{c}\text { Total } \\
\text { group } \\
(N=164)\end{array}$ & $\begin{array}{c}\text { Congestion }^{-} \\
(n=146)\end{array}$ & $\begin{array}{l}\text { Congestion }^{+} \\
\quad(\mathrm{n}=18)\end{array}$ & $\begin{array}{l}\text { Pleural } \\
\text { effusion } \\
(n=152)\end{array}$ & $\begin{array}{l}\text { Pleural } \\
\text { effusion } \\
(n=12)\end{array}$ & $\begin{array}{l}\text { Cardiomegaly }^{-} \\
\quad(n=67)\end{array}$ & $\begin{array}{l}\text { Cardiomegaly }^{+} \\
\quad(n=97)\end{array}$ & $\begin{array}{c}\text { Coronary } \\
\text { Artery Bypass } \\
\text { Grafting }^{-} \\
(n=128)\end{array}$ & $\begin{array}{c}\text { Coronary } \\
\text { Artery Bypass } \\
\text { Grafting }^{+} \\
(n=36)\end{array}$ \\
\hline $\mathrm{FEV}_{1}, \%$ predicted & $93 \pm 18$ & $95 \pm 18$ & $82 \pm 17^{*}$ & $93 \pm 18$ & $84 \pm 17^{\dagger}$ & $98 \pm 16$ & $90 \pm 19^{*}$ & $95 \pm 17$ & $88 \pm 19^{\dagger}$ \\
\hline VC, $\%$ predicted & $104 \pm 17$ & $105 \pm 17$ & $94 \pm 14^{*}$ & $104 \pm 17$ & $94 \pm 13^{*}$ & $110 \pm 14$ & $100 \pm 17 *$ & $106 \pm 16$ & $96 \pm 18 *$ \\
\hline $\mathrm{FEV}_{1} / \mathrm{VC}, \%$ & $68 \pm 8.0$ & $68 \pm 8$ & $65 \pm 8$ & $68 \pm 8$ & $66 \pm 8$ & $68 \pm 9$ & $68 \pm 8$ & $68 \pm 8$ & $68 \pm 9$ \\
\hline $\mathrm{D}_{\mathrm{LCO}} \mathrm{c}$, predicted ${ }^{\ddagger}$ & $76 \pm 16$ & $77 \pm 15$ & $68 \pm 15^{*}$ & $77 \pm 15$ & $66 \pm 18^{*}$ & $79 \pm 16$ & $74 \pm 15^{*}$ & $77 \pm 16$ & $72 \pm 14$ \\
\hline $\begin{array}{c}\mathrm{D}_{\mathrm{LCO}} \mathrm{c} / \mathrm{V}_{\mathrm{A}}, \% \\
\text { predicted }\end{array}$ & $90 \pm 20$ & $90 \pm 19$ & $89 \pm 22$ & $90 \pm 19$ & $88 \pm 24$ & $86 \pm 18$ & $92 \pm 21$ & $89 \pm 20$ & $92 \pm 20$ \\
\hline $\mathrm{V}_{\mathrm{A}}, \%$ predicted $^{\ddagger}$ & $88 \pm 13$ & $89 \pm 13$ & $80 \pm 10^{*}$ & $89 \pm 13$ & $79 \pm 11^{*}$ & $95 \pm 11$ & $84 \pm 12 *$ & $90 \pm 12$ & $81 \pm 14^{*}$ \\
\hline \multicolumn{10}{|c|}{$\begin{array}{l}\text { Data are presented as mean } \pm \mathrm{SD} \text {. } \\
* P<0.05 \text {. } \\
\dagger 0.05 \leq P \leq 0.07 \text {. } \\
\ddagger \text { Analysis was performed in a total of } 153 \text { subjects. } \\
\mathrm{D}_{\mathrm{LCO}}=\text { diffusing capacity for carbon monoxide corrected for hemoglobin concentration } \\
\mathrm{V}_{\mathrm{A}}=\text { alveolar volume }\end{array}$} \\
\hline
\end{tabular}

Table 8. Predictors of Diffusion Impairment According to the Lower Limit of Normal Criteria and Conventional Cutoff Values

\begin{tabular}{|c|c|c|c|c|}
\hline & \multicolumn{4}{|c|}{ Diffusion Impairment } \\
\hline & $\begin{array}{l}\mathrm{D}_{\mathrm{LCO}} \mathrm{c}<\text { Lower } \\
\text { Limit of Normal } \\
\quad \text { (Univariate) }\end{array}$ & $\begin{array}{l}\mathrm{D}_{\mathrm{LCO}} \mathrm{c}<\text { Lower } \\
\text { Limit of Normal } \\
\text { (Multivariate)* }\end{array}$ & $\begin{array}{c}\mathrm{D}_{\mathrm{LCO}} \mathrm{c}<80 \% \\
\text { Predicted } \\
\text { (Univariate) }\end{array}$ & $\begin{array}{l}\mathrm{D}_{\mathrm{LCO}} \mathrm{c}<80 \% \\
\text { Predicted } \\
\text { (Multivariate) } \dagger\end{array}$ \\
\hline Age, y & $1.001(0.971-1.032)$ & NA & $1.023(0.992-1.055)$ & NA \\
\hline Female sex & $2.308(1.049-5.075) \ddagger$ & $2.970(1.257-7.019) \ddagger$ & $1.946(0.853-4.440)$ & NA \\
\hline BMI, $\mathrm{kg} / \mathrm{m}^{2}$ & $0.916(0.847-0.990) \ddagger$ & $0.898(0.821-0.982) \ddagger$ & $0.905(0.838-0.977) \ddagger$ & $0.872(0.796-0.956)$ 末 \\
\hline LVEF, \% & $0.962(0.920-1.006)$ & NA & $0.964(0.921-1.008)$ & NA \\
\hline NYHA class I vs III & $0.298(0.077-1.145)$ & NA & $0.424(0.124-1.451)$ & NA \\
\hline NYHA class II vs III & $1.273(0.467-3.470)$ & NA & $1.380(0.504-3.781)$ & NA \\
\hline Congestion & $2.008(0.678-5.954)$ & NA & $3.263(0.881-12.080)$ & NA \\
\hline Cardiomegaly & $1.823(0.944-3.521)$ & NA & $2.374(1.227-4.592) \ddagger$ & $1.751[0.806-3.806]$ \\
\hline Pack-years & $1.021(1.003-1.038) \ddagger$ & $1.023(1.004-1.043) \ddagger$ & $1.002(1.003-1.041) \ddagger$ & $1.025(1.003-1.048) \ddagger$ \\
\hline Coronary artery bypass grafting & $1.221(0.554-2.690)$ & NA & $1.724(0.749-3.966)$ & NA \\
\hline NT-proBNP, pmol/L & $1.001(1.000-1.002) \ddagger$ & $1.001[0.999-1.002]$ & $1.002(1.000-1.003) \ddagger$ & $1.000[0.999-1.002]$ \\
\hline $\mathrm{V}_{\mathrm{A}}, \%$ predicted & $0.968(0.943-0.994) \ddagger$ & $0.965(0.936-0.995) \ddagger$ & $0.962(0.936-0.989) \ddagger$ & $0.961(0.928-0.994) \ddagger$ \\
\hline ACE-I & $0.944(0.467-1.908)$ & NA & $1.041(0.513-2.111)$ & NA \\
\hline Aldosterone antagonists & $1.800(0.930-3.484)$ & NA & $1.520(0.778-2.972)$ & NA \\
\hline $\begin{array}{l}\text { Data are presented as odds ratios }(\mathrm{CI}) . \\
* \text { Nagelkerke } \mathrm{r}^{2}=0.22 . \\
\dagger \text { Nagelkerke } \mathrm{r}^{2}=0.23 . \\
\ddagger P<0.05 . \\
\mathrm{D}_{\mathrm{LCO}}=\text { diffusing capacity for carbon mon } \\
\mathrm{NA}, \text { not applicable. } \\
\text { BMI = body mass index } \\
\text { LVEF = left ventricular ejection fraction } \\
\mathrm{NT}-\text { proBNP }=\text { N-terminal pro-B natriuretic } \\
\mathrm{V}_{\mathrm{A}}=\text { alveolar volume } \\
\text { ACE-I = angiotensin-converting enzyme in }\end{array}$ & Irected for hemoglobin concen & & & \\
\hline
\end{tabular}

ratio of $\mathrm{FEV}_{1} / \mathrm{FVC}$ to $<0.65$ as a cutoff point (odds ratio [CI] of 3.58 [1.38-9.24], $P=.01)$. No other predictors of airway obstruction were found using either definition (data not shown), and thus a multivariate logistic regression analysis could not be performed.

\section{Discussion}

The current study showed that the definition used for pulmonary function impairment impacts the role of sex and smoking in pulmonary function in subjects with chronic 
heart failure with left ventricular systolic dysfunction. The lower limit of normal criterion identified an extra independent predictor of diffusion impairment compared with the $80 \%$ predicted value; in addition to BMI, pack-years, and $V_{A}$, female sex also turned out to be an independent predictor. A smoking history of $\geq 10$ pack-years was a significant predictor of diffusion impairment and airway obstruction using the lower limit of normal criterion but not using the conventional cutoff values. However, making the conventional cutoff values more stringent by lowering the cutoff point yielded similar results as the lower limit of normal. Lower lung volumes were found in subjects with pulmonary congestion, cardiomegaly, and a history of coronary artery bypass grafting.

In the current study, the conventional cutoff values classified more subjects as having diffusion impairment and airway obstruction compared with the lower limit of normal. This is explained by the physiological decrease of the $\mathrm{FEV}_{1} / \mathrm{FVC}$ ratio with age. The $\mathrm{FEV}_{1}$ declines more rapidly with age than the FVC in normal subjects. ${ }^{24}$ As a result, the fixed ratio of 0.7 that is traditionally used because of its simplicity may lead to overdiagnosis in the elderly and underdiagnosis in younger patients. ${ }^{18}$ Furthermore, the frequently used $80 \%$ predicted value has neither statistical nor physiological validity. ${ }^{15-17}$ Limits of normal as the predicted $\pm 20 \%$ can only be accurate when the variance above and below the predicted regression line is proportional with the predicted value (ie, heteroscedastic: large variance with large values and small variance with small values). However, since this is not the case, because the scatter around the predicted regression line is constant (homoscedastic) in pulmonary function measurements, the $80 \%$ predicted rule of thumb may lead to false-positive diagnosis in the elderly and shorter individuals with smaller predicted values and underdiagnosis in younger and taller patients with larger predicted values. ${ }^{15-17}$

Misdiagnosis of pulmonary function abnormalities by the conventional cutoff values may have interfered with the interpretation of prior research aiming to investigate the impact of heart failure and several clinical variables on pulmonary function. This may explain part of the inconsistencies across the studies. In fact, a smoking history of $\geq 10$ pack-years was a significant predictor of diffusion impairment and airway obstruction using the lower limit of normal criterion but not using the conventional cutoff values. This implies that inclusion of subjects who are incorrectly labeled as having pulmonary dysfunction distorted the effect of smoking on pulmonary function. Indeed, lowering the conventional cutoff values to match the more stringent lower limit of normal and thus avoid overdiagnosis of diffusion impairment and airway obstruction in the elderly produced similar results as the lower limit of normal. Similarly, female sex was an independent predictor of diffusion impairment according to the lower limit of normal but not according to the $80 \%$ predicted value. However, decreasing the cutoff point to define diffusion impairment showed findings comparable to the lower limit of normal. On the other hand, by increasing the lower limit of normal to the 10th percentile, the association between female sex and diffusion impairment was lost (data not shown). This is explained by the fact that the lower ranges of diffusing capacity represented relatively more women than men. In summary, the lower limit of normal criterion identified more predictors of diffusion impairment and airway obstruction compared with conventional cutoff values in subjects with chronic heart failure with left ventricular systolic dysfunction. However, when conventional cutoff points were lowered to match the more stringent lower limit of normal criterion, the same effects were seen.

The effect of different definitions has also been put forward in the study of de Marco et al, ${ }^{25}$ who have shown that the role of age, sex, former smoking, and low BMI on the development of COPD differs according to the definition used to define COPD. They suggested the need for a definition of COPD that is not exclusively based on spirometry.

Little is known about the clinical impact of different criteria of pulmonary dysfunction. Mannino and DiazGuzman $^{26}$ followed up the mortality data of a large number of subjects from the National Health and Nutrition Examination Survey III classified as normal, obstructed, or restricted using conventional cutoff values and the lower limit of normal. They found that subjects classified as normal using the lower limit of normal but obstructed or restricted using conventional cutoff values had a higher risk of mortality than normal subjects in up to $18 \mathrm{y}$ of follow-up. This finding suggests that conventional criteria may identify at-risk patients who would have been missed using the lower limit of normal. This study was limited by the lack of post-bronchodilator pulmonary function test results, outcome parameters other than mortality, and the lack of comparison between subjects with mild airway obstruction according to conventional cutoff values $\left(\mathrm{FEV}_{1} / \mathrm{FVC}<0.7\right.$ and $\mathrm{FEV}_{1} \geq 80 \%$ predicted) and normal subjects according to the lower limit of normal $\left(\mathrm{FEV}_{1} / \mathrm{FVC}, \mathrm{FEV}_{1}\right.$, and $\mathrm{FVC} \geq$ lower limit of normal). More longitudinal studies are warranted to determine which criterion is clinically more relevant in terms of morbidity (symptoms, exercise tolerance, health-related quality of life, hospitalization, use of health recourses) and mortality. Since we did not follow our subjects prospectively, it remains unknown whether pulmonary function impairment had prognostic implications in our study population and whether this is influenced by different definitions of pulmonary dysfunction. Several factors have been implied to play a role in the etiology of pulmonary function impairment in patients with heart failure, including the effects of heart failure itself on pulmonary function in addition to (previously undiagnosed) underlying pulmonary disease 
and confounding influences, such as smoking, coronary artery bypass grafting, and obesity. ${ }^{4-7,13}$

Diffusion impairment has been thought to be related to the thickening of the alveolar-capillary membrane due to hydrostatic mechanical injury, interstitial edema, remodeling, and fibrosis. ${ }^{1,2,4-6,27}$ Because heart transplantation does not affect or may even worsen pulmonary diffusing capacity despite an improvement in hemodynamic status and lung volumes, ${ }^{28}$ it has been suggested that reduced diffusing capacity in chronic heart failure may be related to permanent damage to the alveolar-capillary membrane. ${ }^{2}$ Other possible causes of diffusion impairment in heart failure include reduced lung and pulmonary capillary blood volumes, ventilation-perfusion mismatch, recurrent pulmonary emboli, smoking, and cardiopulmonary bypass. ${ }^{4-6,13}$ The results of our study showed a higher NYHA class, smoking of $\geq 10$ pack-years, pulmonary congestion, pleural effusion, and cardiomegaly to be associated with more impaired diffusing capacity, the latter 3 probably due to their negative effects on lung volume. Indeed, diffusing capacity corrected for $\mathrm{V}_{\mathrm{A}}$ was not significantly different between the groups. Also, although $\mathrm{V}_{\mathrm{A}}$ turned out to be an independent predictor of diffusion impairment, pulmonary congestion and cardiomegaly were not. In contrast to previous reports, ${ }^{29-31}$ the use of angiotensin-converting enzyme inhibitors and aldosterone antagonists was not associated with increased diffusing capacity. Also, diffusing capacity was not significantly different between groups of subjects with or without a history of coronary artery bypass grafting. Independent predictors of diffusion impairment were BMI, pack-years (continuous variable), and $\mathrm{V}_{\mathrm{A}}$, whereas the role of sex and of having smoked $\geq 10$ packyears depended on the definition used to define diffusion impairment. Although the underlying mechanisms are not clear, women seemed to be more sensitive to the detrimental effects of heart failure on diffusing capacity. Sex differences in pulmonary function have been recognized before but not specifically in the heart failure population. Adult women have been reported to have lower resting lung diffusing capacity corrected for hemoglobin, smaller lung volumes, and lower maximal expiratory flows, even when corrected for age and standing height relative to men. ${ }^{32}$ It has been suggested that these sex differences in part can be explained by pulmonary structural differences (fewer total number of alveoli and smaller airway diameter relative to lung size) and hormonal influences in women. ${ }^{32}$ More research is needed regarding the influence of sex on pulmonary function in general and specifically in the heart failure population. The protective association between a higher BMI and less likelihood of having diffusion impairment has not, to our knowledge, been described before in subjects with chronic heart failure. However, some studies in healthy obese non-smokers have suggested that dif- fusing capacity may be increased in extremely obese subjects, probably as a result of the increase in blood volume. ${ }^{33}$

Restriction has been linked to cardiomegaly, pleural effusion, respiratory muscle weakness, coronary artery bypass grafting, fibrosis from chronic congestion, and reduced lung compliance due to chronic vascular engorgement, interstitial/alveolar fluid accumulation, and chronic remodeling of the pulmonary vasculature due to elevated left atrial pressure. ${ }^{1,4-6,13,34,35}$ In line with expectations, we found lung volumes to be lower in subjects with pulmonary congestion, pleural effusion, cardiomegaly, and a history of coronary artery bypass grafting.

Airway obstruction has been attributed to alveolar fluid accumulation, bronchial mucosal swelling, peribronchial edema and fibrosis, squamous metaplasia of bronchial epithelial cells induced by transforming growth factor- $\beta$ from the failing heart, geometric decrease in airway size from reduction in lung volume, abnormalities of autonomic control, neurohumoral bronchoconstriction, bronchial hyperresponsiveness, and smoking, ${ }^{4-7,13,36}$ although results are not consistent. ${ }^{14}$ Our study showed a greater impaired $\mathrm{FEV}_{1} / \mathrm{VC}$ ratio in subjects who had smoked $\geq 10$ packyears. Also, having smoked $\geq 10$ pack-years was a significant predictor of airway obstruction, but this depended on the definition used to define airway obstruction. Although we excluded patients with known COPD or other obstructive lung disease, we cannot rule out the possibility that some of the subjects with airway obstruction had previously undiagnosed COPD, because most subjects were current or former smokers. In fact, $16 \%$ (lower limit of normal) to $24 \%$ (conventional cutoff values) of the subjects had post-bronchodilator airway obstruction after inhaling $400 \mu \mathrm{g}$ salbutamol and $80 \mu \mathrm{g}$ atrovent. These subjects had more symptoms of cough and sputum than those without post-bronchodilator airway obstruction (data not shown). Also, subjects who were current or former smokers tended more often to have post-bronchodilator airway obstruction than those who had never smoked (lower limit of normal: $19 \%$ vs $6 \%, P=.06$; conventional cutoff values: $27 \%$ vs $11 \%, P=.05)$. However, hyperinflation, which has been found to be a valid indicator of true COPD in patients with congestive heart failure, ${ }^{37}$ was not significantly different between groups of subjects with persistent airway obstruction after bronchodilation and those with reversible airway obstruction (data not shown). Although airway obstruction in heart failure has also been attributed to pulmonary congestion, the $\mathrm{FEV}_{1} / \mathrm{VC}$ ratio was not significantly different between groups of subjects with and without pulmonary congestion in our study, which does not exclude the contribution of pulmonary congestion to small airway obstruction.

Importantly, airway obstruction may lead to hyperinflation of the lungs due to expiratory flow limitation and air trapping, which was found in almost half of our subjects 
with airway obstruction as defined by an increased residual volume/TLC ratio. This may contribute to symptoms of dyspnea, poor exercise tolerance, increased work of breathing and oxygen consumption, respiratory muscle dysfunction, and adverse impact on cardiac function by decreasing the preload. ${ }^{38}$ Thus, irrespective of the causes, pulmonary function abnormalities associated with chronic heart failure may explain part of the symptoms and functional disability encountered in these subjects. ${ }^{8-12}$ Moreover, pulmonary function impairment increases with the severity of heart failure, ${ }^{9,11}$ provides important prognostic information, ${ }^{39-42}$ and may ameliorate or normalize with several treatment modalities, such as pharmacologic and nonpharmacologic treatment of heart failure ${ }^{2,28,43-46}$ and antiobstructive therapy with bronchodilators. ${ }^{47-53}$ Pulmonary function might thus be used as a guide for the evaluation of patients with chronic heart failure, with respect to severity of disease, prognosis, and response to treatment.

Some limitations of this study deserve further discussion. It is important to realize that these results may not be applicable to all patients with chronic heart failure, since we did not include subjects with preserved systolic function, who seem to have less impaired pulmonary function. ${ }^{54}$ Furthermore, patients with more severe heart failure could have been underrepresented in this study because of an inability to participate, and thus pulmonary function abnormalities might have been underestimated. Finally, considering the relatively small number of subjects included in the current study, in particular women and nonsmokers, further research is needed to confirm our results.

\section{Conclusions}

In conclusion, the lower limit of normal identifies sex as an extra predictor of diffusion impairment and a smoking history of $\geq 10$ pack-years as an additional predictor of both diffusion impairment and airway obstruction compared with conventional cutoff values in subjects with chronic heart failure with left ventricular systolic dysfunction. However, when conventional cutoff points were lowered to match the more stringent lower limit of normal criterion, the same effects were seen. Our results stress the need for clear definitions of pulmonary function abnormalities. More longitudinal studies are warranted to determine which criterion is clinically more relevant. Specifically, future research should focus on better characterizing the potentially misclassified group of patients who are above the lower limit of normal but below the conventional cutoff values. Do these patients have a worse outcome with higher morbidity and mortality rates that is amenable to treatment, or do they present with clinical features similar to those with chronic heart failure but without pulmonary dysfunction? Finally, more research is needed regarding the influence of sex on pulmonary func- tion in the heart failure population and the possible underlying pathophysiologic mechanisms.

\section{ACKNOWLEDGMENTS}

We thank the participants in this study for their cooperation. We also thank the nurse practitioners PA Ninaber, WAM Janssen, and WH van Zimmeren-Feijen and heart failure nurse JG Froon-Elferink for their contribution to inclusion of participants and data collection. We owe much gratitude to the pulmonary function and clinical chemistry and hematology laboratories as well as the echocardiography and radiology departments for their assistance in data collection. Also, we acknowledge Dr PH Quanjer for his contribution to the manuscript and biostatistician ART Donders for his contribution to statistical analysis.

\section{REFERENCES}

1. Kee K, Naughton MT. Heart failure and the lung. Circ J 2010; 74(12):2507-2516

2. Guazzi M. Alveolar gas diffusion abnormalities in heart failure. J Card Fail 2008;14(8):695-702.

3. Agostoni P, Cattadori G, Bussotti M, Apostolo A. Cardiopulmonary interaction in heart failure. Pulm Pharmacol Ther 2007;20(2):130-134.

4. Gehlbach BK, Geppert E. The pulmonary manifestations of left heart failure. Chest 2004;125(2):669-682.

5. Chua TP, Coats AJ. The lungs in chronic heart failure. Eur Heart J 1995; 16(7):882-887.

6. Faggiano P. Abnormalities of pulmonary function in congestive heart failure. Int J Cardiol 1994;44(1):1-8.

7. Snashall PD, Chung KF. Airway obstruction and bronchial hyperresponsiveness in left ventricular failure and mitral stenosis. Am Rev Respir Dis 1991;144(4):945-956.

8. Mancini DM. Pulmonary factors limiting exercise capacity in patients with heart failure. Prog Cardiovasc Dis 1995;37(6):347-370.

9. Puri S, Baker BL, Dutka DP, Oakley CM, Hughes JM, Cleland JG. Reduced alveolar-capillary membrane diffusing capacity in chronic heart failure. Its pathophysiological relevance and relationship to exercise performance. Circulation 1995;91(11):2769-2774.

10. Kraemer MD, Kubo SH, Rector TS, Brunsvold N, Bank AJ. Pulmonary and peripheral vascular factors are important determinants of peak exercise oxygen uptake in patients with heart failure. J Am Coll Cardiol 1993;21(3):641-648.

11. Dimopoulou I, Daganou M, Tsintzas OK, Tzelepis GE. Effects of severity of long-standing congestive heart failure on pulmonary function. Respir Med 1998;92(12):1321-1325.

12. Tzani P, Piepoli MF, Longo F, Aiello M, Serra W, Maurizio AR, et al. Resting lung function in the assessment of the exercise capacity in patients with chronic heart failure. Am J Med Sci 2010;339(3): 210-215.

13. Johnson BD, Beck KC, Olson LJ, O'Malley KA, Allison TG, Squires RW, Gau GT. Pulmonary function in patients with reduced left ventricular function: influence of smoking and cardiac surgery. Chest 2001;120(6):1869-1876.

14. Wright RS, Levine MS, Bellamy PE, Simmons MS, Batra P, Stevenson $\mathrm{LW}$, et al. Ventilatory and diffusion abnormalities in potential heart transplant recipients. Chest 1990;98(4):816-820.

15. Sobol BJ, Sobol PG. Per cent of predicted as the limit of normal in pulmonary function testing: a statistically valid approach. Thorax 1979;34(1):1-3.

16. Pellegrino R, Viegi G, Brusasco V, Crapo RO, Burgos F, Casaburi $\mathrm{R}$, et al. Interpretative strategies for lung function tests. Eur Respir J 2005;26(5):948-968.

17. Minasian AG, van den Elshout FJ, Dekhuijzen PN, Vos PJ, Willems FF, van den Bergh PJ, Heijdra YF. Pulmonary function impairment 


\section{Predictors of Pulmonary Function Impairment in Chronic Heart Failure}

in patients with chronic heart failure: lower limit of normal versus conventional cutoff values. Heart Lung 2014;43(4):311-316.

18. Miller MR, Quanjer PH, Swanney MP, Ruppel G, Enright PL. Interpreting lung function data using 80 percent of predicted and fixed thresholds misclassifies over 20\% of patients. Chest 2011;139(1):52-59.

19. Dickstein K, Cohen-Solal A, Filippatos G, McMurray JJ, Ponikowski P, Poole-Wilson PA, et al. ESC Guidelines for the diagnosis and treatment of acute and chronic heart failure 2008: the Task Force for the Diagnosis and Treatment of Acute and Chronic Heart Failure 2008 of the European Society of Cardiology. Developed in collaboration with the Heart Failure Association of the ESC (HFA) and endorsed by the European Society of Intensive Care Medicine (ESICM). Eur Heart J 2008;29(19):2388-2442.

20. O'Hanlon R, O'Shea P, Ledwidge M, O'Loughlin C, Lange S, Conlon $\mathrm{C}$, et al. The biologic variability of B-type natriuretic peptide and $\mathrm{N}$-terminal pro-B-type natriuretic peptide in stable heart failure patients. J Card Fail 2007;13(1):50-55.

21. Quanjer PH, Tammeling GJ, Cotes JE, Pedersen OF, Peslin R, Yernault JC. Lung volumes and forced ventilatory flows. Report Working Party Standardization of Lung Function Tests, European Community for Steel and Coal. Official Statement of the European Respiratory Society. Eur Respir J Suppl 1993;16:5-40.

22. Rabe KF, Hurd S, Anzueto A, Barnes PJ, Buist SA, Calverley P, et al. Global strategy for the diagnosis, management, and prevention of chronic obstructive pulmonary disease: GOLD executive summary. Am J Respir Crit Care Med 2007;176(6):532-555.

23. Bourjeily-Habr G, Rochester CL, Palermo F, Snyder P, Mohsenin V. Randomised controlled trial of transcutaneous electrical muscle stimulation of the lower extremities in patients with chronic obstructive pulmonary disease. Thorax 2002;57(12):1045-1049.

24. Townsend MC. Conflicting definitions of airways obstruction: Drawing the line between normal and abnormal. Chest 2007;131(2):335-336.

25. de Marco R, Accordini S, Marcon A, Cerveri I, Anto JM, Gislason $\mathrm{T}$, et al. Risk factors for chronic obstructive pulmonary disease in a European cohort of young adults. Am J Respir Crit Care Med 2011; 183(7):891-897

26. Mannino DM, Diaz-Guzman E. Interpreting lung function data using $80 \%$ predicted and fixed thresholds identifies patients at increased risk of mortality. Chest 2012;141(1):73-80.

27. Guazzi M. Alveolar-capillary membrane dysfunction in chronic heart failure: pathophysiology and therapeutic implications. Clin Sci 2000; 98(6):633-641.

28. Bussières LM, Pflugfelder PW, Ahmad D, Taylor AW, Kostuk WJ. Evolution of resting lung function in the first year after cardiac transplantation. Eur Respir J 1995;8(6):959-962.

29. Guazzi M, Melzi G, Agostoni P. Comparison of changes in respiratory function and exercise oxygen uptake with losartan versus enalapril in congestive heart failure secondary to ischemic or idiopathic dilated cardiomyopathy. Am J Cardiol 1997;80(12):1572-1576.

30. Guazzi M, Marenzi G, Alimento M, Contini M, Agostoni P. Improvement of alveolar-capillary membrane diffusing capacity with enalapril in chronic heart failure and counteracting effect of aspirin. Circulation 1997;95(7):1930-1936

31. Guazzi M, Agostoni P, Guazzi MD. Modulation of alveolar-capillary sodium handling as a mechanism of protection of gas transfer by enalapril, and not by losartan, in chronic heart failure. J Am Coll Cardiol 2001;37(2):398-406.

32. Harms CA, Rosenkranz S. Sex differences in pulmonary function during exercise. Med Sci Sports Exerc 2008;40(4):664-668.

33. Salome CM, King GG, Berend N. Physiology of obesity and effects on lung function. J Appl Physiol 2010;108(1):206-211.

34. Olson TP, Beck KC, Johnson BD. Pulmonary function changes associated with cardiomegaly in chronic heart failure. J Card Fail 2007;13(2):100-107.
35. Agostoni P, Cattadori G, Guazzi M, Palermo P, Bussotti M, Marenzi G. Cardiomegaly as a possible cause of lung dysfunction in patients with heart failure. Am Heart J 2000;140(5):e24.

36. Tanabe T, Kanoh S, Moskowitz WB, Rubin BK. Cardiac asthma: TGF- $\beta$ from the failing heart leads to squamous metaplasia in human airway cells and in the murine lung. Chest 2012;142(5):1274-1283.

37. Brenner S, Güder G, Berliner D, Deubner N, Fröhlich K, Ertl G, et al. Airway obstruction in systolic heart failure: COPD or congestion? Int J Cardiol 2013;168(3):1910-1916.

38. Rossi A, Aisanov Z, Avdeev S, Di Maria G, Donner CF, Izquierdo $\mathrm{JL}$, et al. Mechanisms, assessment and therapeutic implications of lung hyperinflation in COPD. Respir Med 2015;109(7):785-802.

39. Guazzi M, Pontone G, Brambilla R, Agostoni P, Rèina G. Alveolarcapillary membrane gas conductance: a novel prognostic indicator in chronic heart failure. Eur Heart J 2002;23(6):467-476.

40. Iversen KK, Kjaergaard J, Akkan D, Kober L, Torp-Pedersen C, Hassager $\mathrm{C}$, et al. The prognostic importance of lung function in patients admitted with heart failure. Eur J Heart Fail 2010;12(7):685-691.

41. Hawkins NM, Petrie MC, Jhund PS, Chalmers GW, Dunn FG, McMurray JJ. Heart failure and chronic obstructive pulmonary disease: diagnostic pitfalls and epidemiology. Eur J Heart Fail 2009; 11(2):130-139.

42. O'Kelly N, Robertson W, Smith J, Dexter J, Carroll-Hawkins C, Ghosh S. Short-term outcomes in heart failure patients with chronic obstructive pulmonary disease in the community. World J Cardiol 2012;4(3):66-71

43. Light RW, George RB. Serial pulmonary function in patients with acute heart failure. Arch Intern Med 1983;143(3):429-433.

44. Faggiano P, Lombardi C, Sorgato A, Ghizzoni G, Spedini C, Rusconi C. Pulmonary function tests in patients with congestive heart failure: effects of medical therapy. Cardiology 1993;83(1):30-35.

45. Niset G, Ninane V, Antoine M, Yernault JC. Respiratory dysfunction in congestive heart failure: correction after heart transplantation. Eur Respir J 1993;6(8):1197-1201.

46. Petersen CL, Kjaer A. Impact of medical treatment on lung diffusion capacity in elderly patients with heart failure. Baseline characteristics and 1-year follow up after medical treatment. Int $\mathrm{J}$ Cardiol 2005;98(3):453-457.

47. Minasian AG, van den Elshout FJ, Dekhuijzen PN, Vos PJ, Willems FF, van den Bergh PJ, Heijdra YF. Bronchodilator responsiveness in patients with chronic heart failure. Heart Lung 2013; 42(3):208-214

48. Kindman LA, Vagelos RH, Willson K, Prikazky L, Fowler M. Abnormalities of pulmonary function in patients with congestive heart failure, and reversal with ipratropium bromide. Am J Cardiol 1994; 73(4):258-262

49. Uren NG, Davies SW, Jordan SL, Lipkin DP. Inhaled bronchodilators increase maximum oxygen consumption in chronic left ventricular failure. Eur Heart J 1993;14(6):744-750.

50. Khan KA, Jalal S, Jan VM, Lone GM, Jan R, Alai MS, et al Pulmonary function profile in chronic congestive heart failure and the effect of ipratropium bromide. Indian Heart J 2000;52(3):297-300.

51. Witte KK, Morice A, Cleland JG, Clark AL. The reversibility of increased airways resistance in chronic heart failure measured by impulse oscillometry. J Card Fail 2004;10(2):149-154.

52. Rolla G, Bucca C, Brussino L, Gallo W, Malara D. Bronchodilating effect of ipratropium bromide in heart failure. Eur Respir J 1993; 6(10):1492-1495.

53. Ng TM, Munger MA, Lombardi WL, Doing TH, Ryujin DT, Young DC, Lugo RA. Chronically inhaled salmeterol improves pulmonary function in heart failure. J Cardiovasc Pharmacol 2002;40(1):140-145.

54. Kurzawa R, Baron T, Grodzicki T. Pulmonary function test abnormalities in the elderly with systolic heart failure. Kardiol Pol 65(8): 875-880, 2007; discussion 881-872. 